\title{
FINITE ELEMENT MODELLING OF CUTTING FORCE COMPONENTS IN FACE MILLING
}

\author{
Csaba Felhő \\ associate professor, Institute of Manufacturing Science, University of Miskolc \\ 3515 Miskolc, Miskolc-Egyetemváros, e-mail: ggytfcs@uni-miskolc.hu
}

\begin{abstract}
This paper presents a study about the Finite Element Modelling of cutting force components acting on the workpiece $(F x, F y, F z)$ in face milling. The values of the three force components were simulated by the FEM software AdvantEdge by Third Wave Systems. This program is uniquely intended for modelling of cutting processes. It is introduced how to measure the cutting edge radius of the insert by optical method. The simulated cutting force values were compared with real measurement data, and a good correlation was found between them.
\end{abstract}

Keywords: Finite Element Modelling, Face milling, Cutting force components.

\section{Introduction}

Milling is one of the most versatile types of machining because it is suitable for producing the most diverse surfaces. It is a productive machining process that uses a single or multi-insert cutting tool, which means that the tool works with several edges at the same time, and even with new and modern tool materials, productivity can be multiplied. Milling machines are primarily used to produce flat, planar, composite, other shaped surfaces and can be used to create more complex shapes as well. Face milling is one of the most commonly used milling method. It is used primarily to produce flat surfaces, because this is one of the most economical ways to cut such surfaces. This is especially due priority in today's automotive industry-concentrated production, where even the smallest cost reductions play a huge role in the optimization of high-volume production. During the optimization of process parameters in face milling, the knowledge of the cutting force and power requirement values are especially important. The determination of the cutting force values can be done by different approaches: by cutting force measurements, by theoretical calculations with different formulas, like the well-known Kienzle-Victor equation [1], or by Finite Element Modelling. Every method has its advantages and disadvantages. The experimental method is a proven and reliable method for determining the cutting force, but it has a significant instrumentation requirement and is quite time consuming. Methods based on calculations are relatively quickly and inexpensively deployable, and they are capable to approximate the cutting force and power values with good accuracy, but this is largely depending on the applied method and the chosen values. This is due to the fact, that they are often based on some assumptions which are difficult to verify [2]. Nonetheless, these are important methods that are most commonly used, and both model refinements and new computational methods and are continuously emerging, e.g. $[3,4,5]$. The third mentioned way is to utilize Finite Element Modelling. This is not an easy to use method, as it needs significant knowledge about the different insights of the Finite Element Method (FEM). However, FEM simulation of the cutting process can provide more details on the chip for- 
mation process, and it can be used to verify or clarify the assumptions for analytical calculations. Therefore, finite element simulations should be considered as high-level, highly specialized but rather important procedures. A review of the relevant literature also shows that a large number of researchers have had and are currently working on finite element simulation of different machining processes [6,7]. There are many types of FEM software available, and some have been specifically developed for modelling machining processes [8].

This paper is focused on the using of the ThirdWave AdvantEdge Finite Element Method software for the determination of cutting force components in face milling. It will be presented, how to set-up a model for the simulation, how to evaluate the obtained data, and how to compare the results with experimental values.

\section{Methods}

\subsection{Cutting parameters}

During the research, the modelling of the face milling process was performed, as well as real machining experiments were performed to validate the modelling results. The applied cutting parameters are introduced in the following. The applied cutting tool was a Sandvik Coromant R200-068Q27-12L milling head with an RCKT 1204M0-PM4230 cutting insert (Fig. 1.). Only a single cutting insert was utilized during the investigations, as it is easier to understand the cutting force values in that case [9]. It is true for both the simulation and experimental investigations.

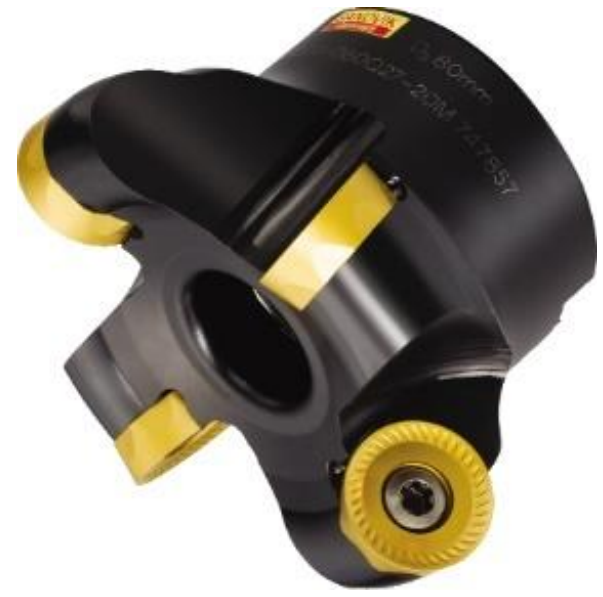

a)

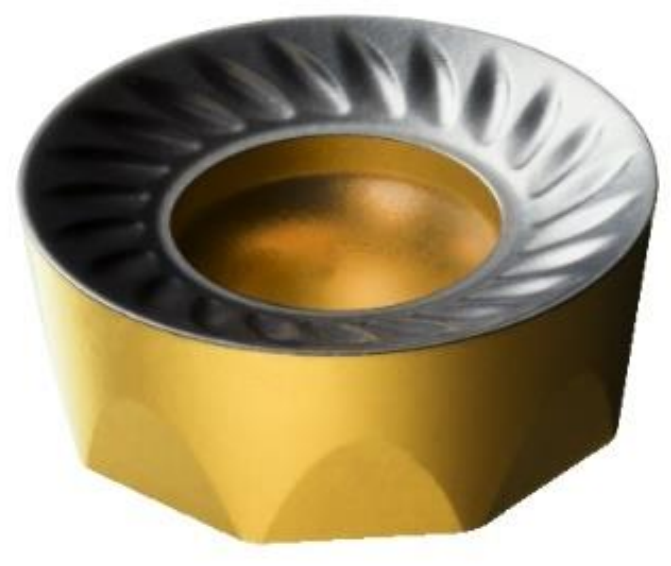

b)

Figure 1. The applied cutting tool: a) milling head, b) cutting insert [10]

An important aspect of finite element investigations is to map the real conditions of the machining as accurately as possible. However, tool manufacturers do not provide all the details of the tools they sell that are needed for the development of the model. Such as, for example, the value of the cutting edge radius, which directly affects the chip removal process and the value of the minimum chip thickness that can be removed. Therefore, we have developed a method for measuring the radius of the cutting edge. The measurements were performed on an Altisurf 520 three-dimensional surface roughness 
measuring device which has three different measuring heads: an inductive gauge, a confocal chromatic probe and a laser sensor. Each of those has its advantages and disadvantages according to their different characteristics: the inductive sensor is good for accurate measurements especially in internal features e.g. in holes, where the optical sensors cannot be utilized. The confocal chromatic probe (we have two sensors, CL2/MG140 and CL4/MG35) can be used for accurate measurements on external features, and it can be used for three-dimensional measurements as it is fast enough for that. And the laser sensor (LK-G32) is good when the surface is more rough, or the features to be measured has some form, and it should be followed during the measurements, as its measurement range is quite large. Therefore, it can be used for the measurement of the edge radius of cutting tools: it can follow the shape of the tool from the flank through the edge to the rake face as it can be seen on Fig. 2.
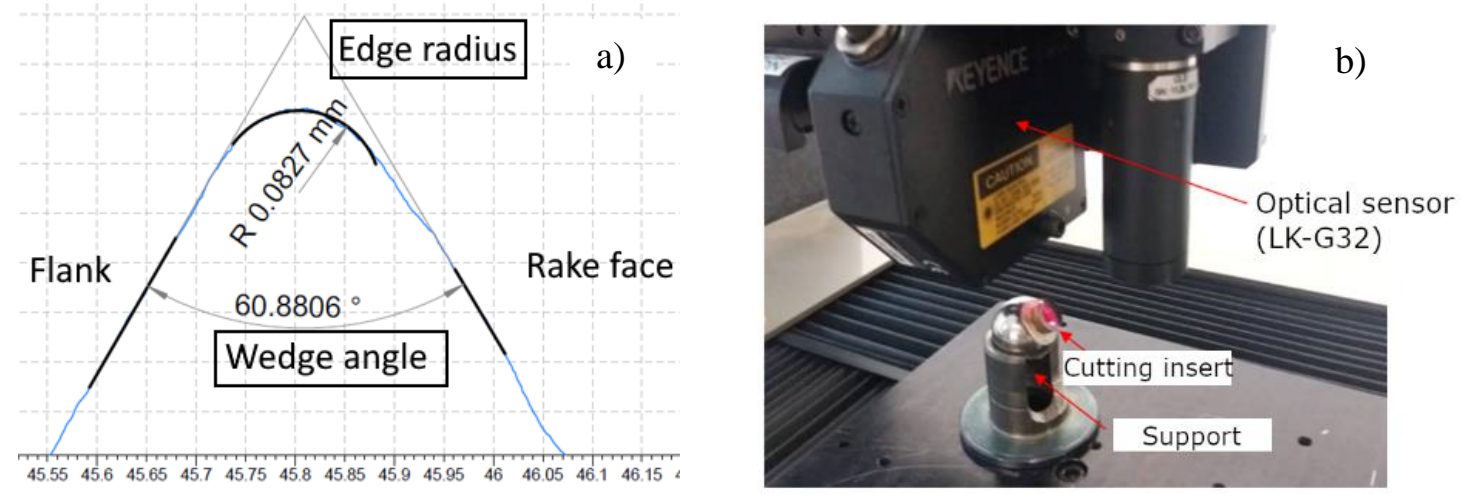

Figure 2. Measurement of the cutting edge radius with laser sensor a) measured profile, b) measurement setup

For the workpiece geometry used in the modeling and experiments, a simple block shape was used (with dimensions of $59 \times 50 \times 50 \mathrm{~mm}$ ), but it should be noted that in finite element modeling it is advisable to reduce its dimensions and to provide only the immediate vicinity of the cutting zone. The material of the workpiece is C45, its hardness is about $200 \mathrm{HB}$.

The applied cutting parameters were the following:

- cutting head working diameter: $\mathrm{D}_{\mathrm{s}}=68 \mathrm{~mm}$;

- nose radius of the cutting insert: $\mathrm{r}_{\varepsilon}=6 \mathrm{~mm}$ (round insert with $\mathrm{iC}=12 \mathrm{~mm}$ );

- edge radius of the cutting insert: $\mathrm{r}_{\beta}=0.08 \mathrm{~mm}$ (measured 5 times with the above described method, and the values were averaged);

- cutting speed: $\mathrm{v}_{\mathrm{c}}=150 \mathrm{~m} / \mathrm{min}$.;

- depth of cuts in two directions: $\mathrm{a}_{\mathrm{p}}=0.31 \mathrm{~mm}$ (axial); $\mathrm{a}_{\mathrm{e}}=59 \mathrm{~mm}$ (radial);

- feed per tooth: $\mathrm{f}_{\mathrm{z}}=0.26 \mathrm{~mm}$.

Cutting experiments were performed on a Perfect Jet MCV-M8 vertical CNC milling machine. The following equipment was used to measure the cutting force components: a Kistler 9257A threecomponent dynamometer, 3 pcs Kistler 5011A charge amplifiers, a National Instruments 92154 Channel, 10V, 16-bit, Simultaneous Analog Input Module which was installed in an NI cDAQ-9171 USB Chassis. This Data Acquisition (DAQ) device was connected to a portable computer, where the Labview software was used for the data processing with a self-made measurement program. This 
measurement system can record the Fx, Fy and Fz cutting force components, which are acting on the workpiece. Fig. 3. shows their interpretation in an arbitrary angle position $\varphi$, and their relation to the other force components.

Knowledge of the feed force applied to the workpiece $(\mathrm{Fx})$ from the components of the cutting force at milling is likewise extremely important as the cutting force at Fc. The Fx component loads the feeding mechanism of the machine tool and try to move the workpiece on the machine table [12]. The Fy force is a component of the main cutting force $\mathrm{Fc}$, which are assumed to be equal to each other at an angular position of $\varphi=90^{\circ}$. The magnitude of the force component in the $\mathrm{z}$ direction $(\mathrm{Fz})$ is equal to the passive force Fp. The value of the main cutting force is usually 3-5 times higher than that of the components of the other cutting forces and, together with the cutting speed, is the determining parameter of the cutting power. The dynamic stability of the milling head is strongly related to the direction of the cutting force. In reality, cutting force is a distributed force in the area of chip cross-section, but for simplicity it is considered a concentrated force whose point of attack must be clearly defined [13].

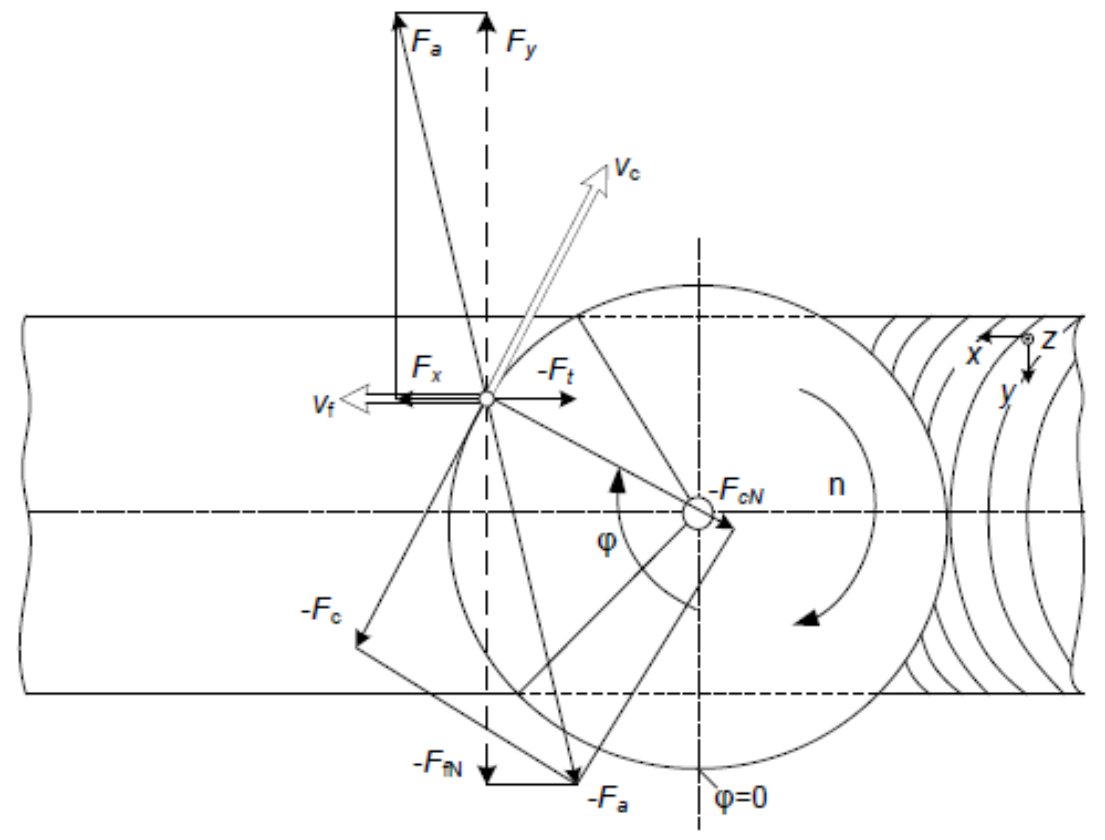

Figure 3. Force relations during face milling at an arbitrary angle $\varphi$ [11]

\subsection{Simulation parameters}

The ThirdWave AdvantEdge software was used for the investigations. This software is especially made for modelling of different metal cutting operations where the tool has defined edge geometry (i.e. its rake, clearance, and wedge angles are known). It has both two- and three-dimensional modelling possibilities. The 2D modelling is good for simpler cases, e.g. for orthogonal turning, while the 3D simulation can be used to analyze milling or drilling processes among others. In the current investigations, face milling was analyzed, so the 3D modelling was utilized. So, the first step during the simulation model set-up is to select the process types, and then to define the workpiece characteristics. The applied parameters, and the workpiece material are shown in Fig. 4. 


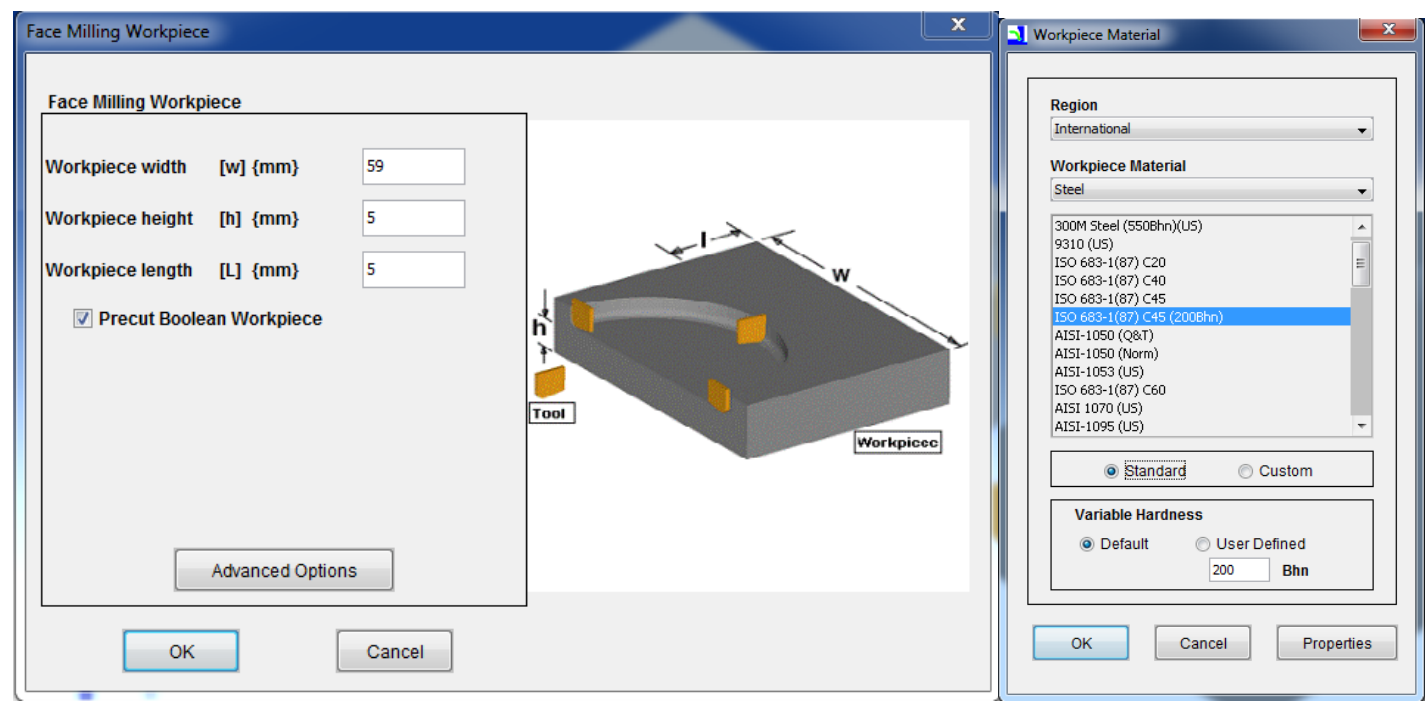

Figure 4. Setting the workpiece parameters

It is worth mentioning the "Precut boolean workpiece" option here, which allows the program to start the simulation when the tool has completely penetrated the material, so the cutting process is stable. This is applicable if we do not aim to examine the contact and entry conditions. The chosen workpiece material is ISO 683-1(87) C45 (200Bhn). When modeling the cutting insert in AdvantEdge, it is important to emphasize that only the part that is involved in cutting needs to be modeled in the software. This helps keep the computation time in check, otherwise the computation algorithm will have to count the part that is not affected by the machining. The tool modelling can be seen on Fig. 5.

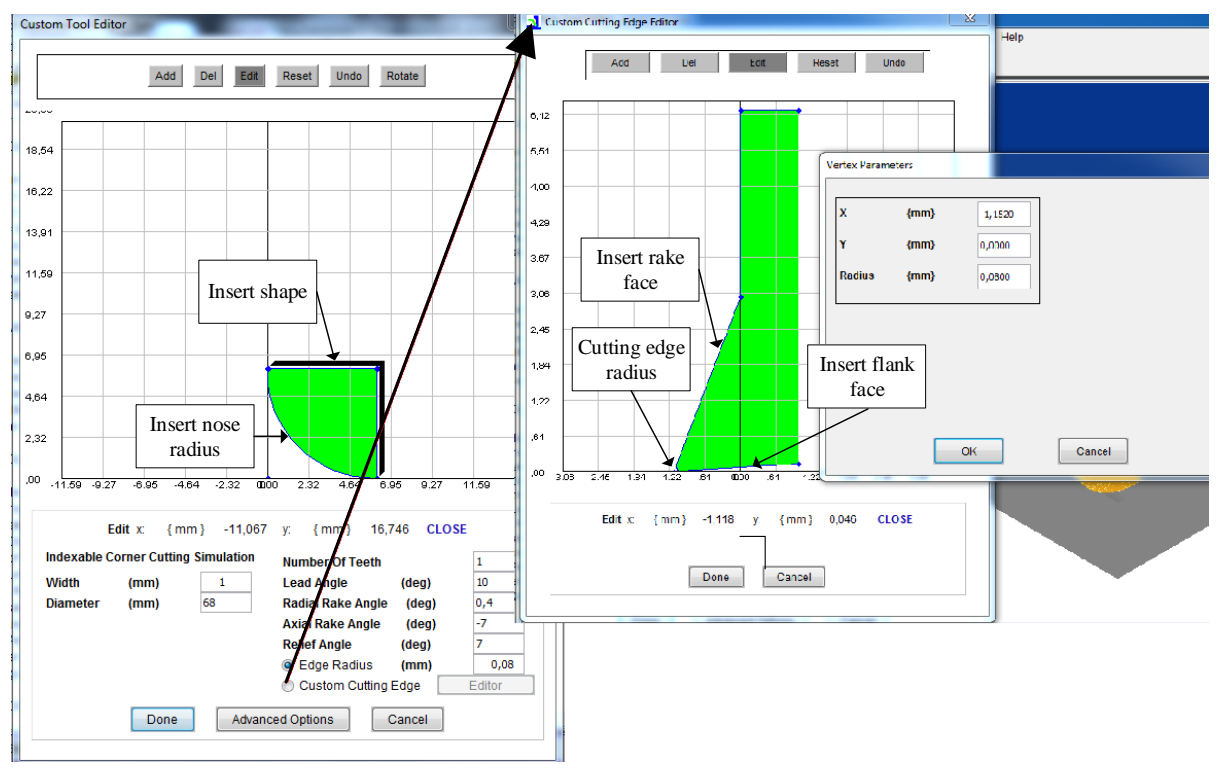

Figure 5. Modelling of the cutting tool in the FEM software 
On the left side of the figure, the cutting tool shape was defined in the "Tool Reference Plane" (Pr). Here, the nose radius of the cutting insert can be modelled; in this case it was $6 \mathrm{~mm}$, due to the round insert shape. It should be noted that the image shows a "mirrored" representation of the cutting tool shape, according to the European projection mode, that is used in the edge geometry in our region. However, the software is made in America, so it uses the projection method which is applied there.

As shown in Figure 6, it is possible to describe the geometry (radius) of the cutting edge after activating the "Custom Cutting Edge" option. Here the cutting tool can be seen in the orthogonal section, and the radius of the edge can be defined, which in this case was $0.8 \mathrm{~mm}$. This is a very important characteristic of the cutting tool during FEM simulation (and in the real cutting process as well), whereas the radius of the cutting edge affects the values of the cutting force components, tool wear and the roughness of the generated surface as well [13]. According to the cutting forces, generally it can be stated, that the lower edge radius will produce lower cutting forces, as the sharper tool can penetrate easier to the material. However, the lower edge radius means higher tool wear, since the sharp edge can wear off quickly [14]. According to the surface roughness, the higher edge radius also can be advantageous in terms of surface quality [15].

After carefully defining the cutting tool, the other parameters of the process were set: the previously mentioned cutting data, as well as the values of the features required for meshing the tool and the workpiece and other data for finite element runs, to which the default values offered by the program were applied.

\section{Results and Discussion}

After running the simulation, the data were evaluated. In the current study, the values of the cutting force components are presented, but the software is able to provide much more data about the cutting process. Cutting force data were evaluated in the Tecplot software for both FEM simulation and cutting experiments. Fig. 6 shows the results of simulation and real force measurements for one machining period. It can be seen that the curves of the two graphs follow each other relatively well and the values are also very close to each other. This means that during simulation setup, values close to real-world conditions have been set.
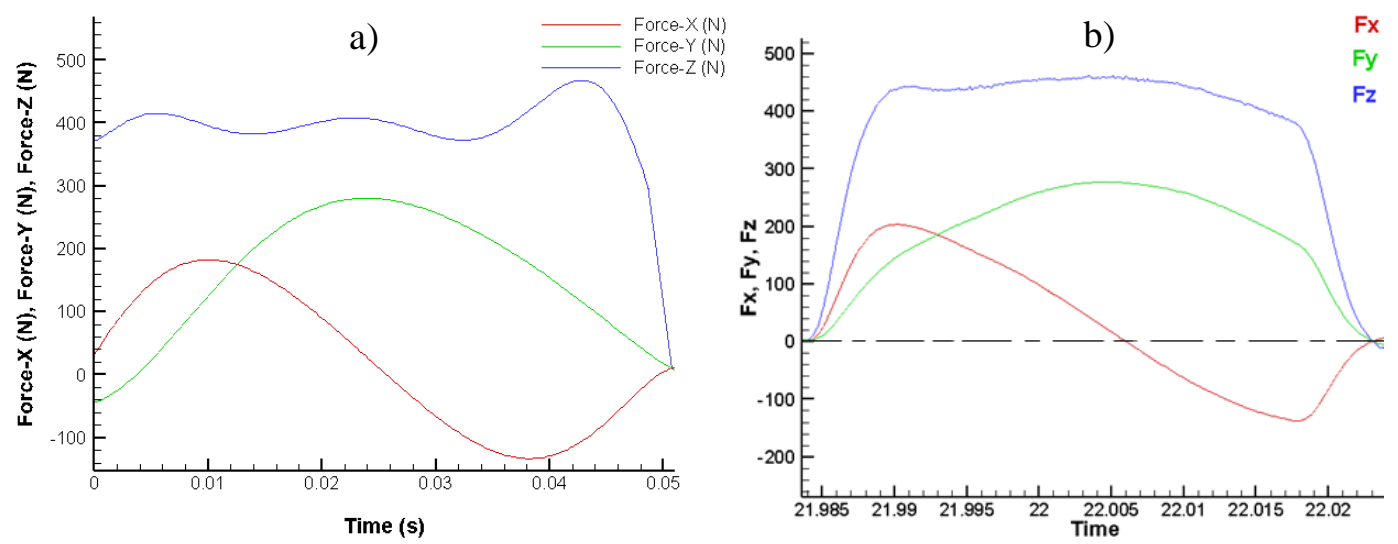

Figure 6. Cutting force component for one cutting period: a) simulated; b) measured 


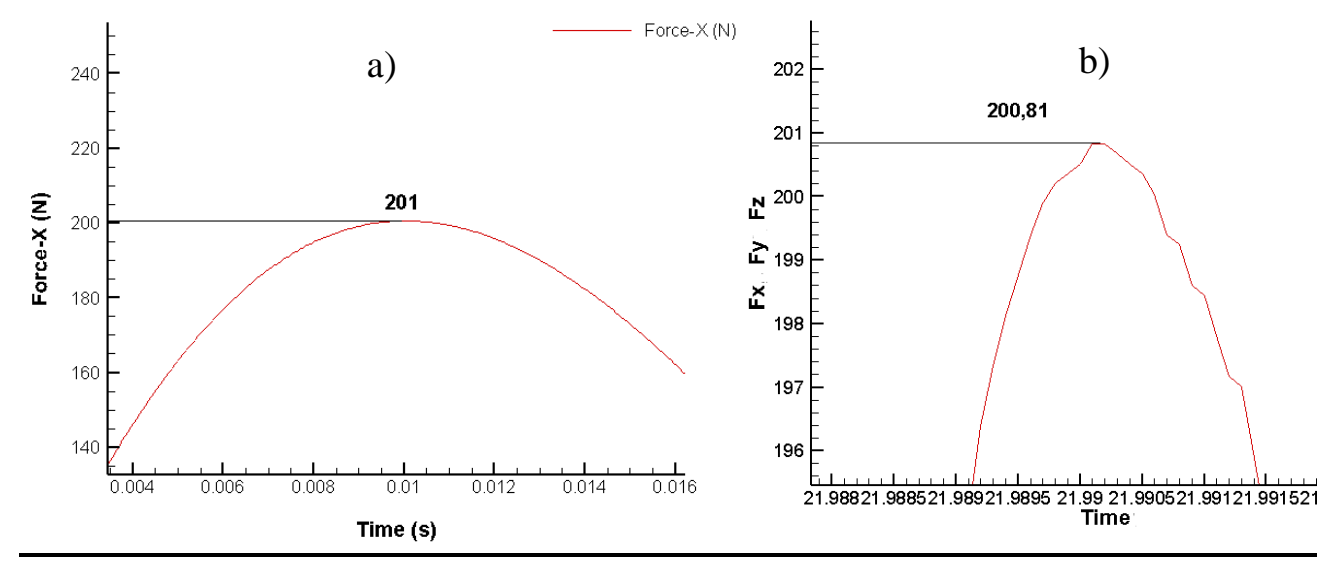

Figure 7. Simulated and measured force values for Fx: a) simulated; b) measured

The highest section of the graph of the Fx force component is depicted in Fig. 7. The force Fx contains one component of the main cutting force Fc, which is the component in the $\mathrm{x}$ direction. The force $\mathrm{Fx}$ passes into the negative range because the component of the $\mathrm{Fc}$ in the $\mathrm{x}$ direction rotates with the tool and it acts in the opposite direction from the middle of the chip removal period (from the centerline of the cutter). However, its maximal value can be read from the graph, which is at around $201 \mathrm{~N}$ for both the simulation and for the measurements.
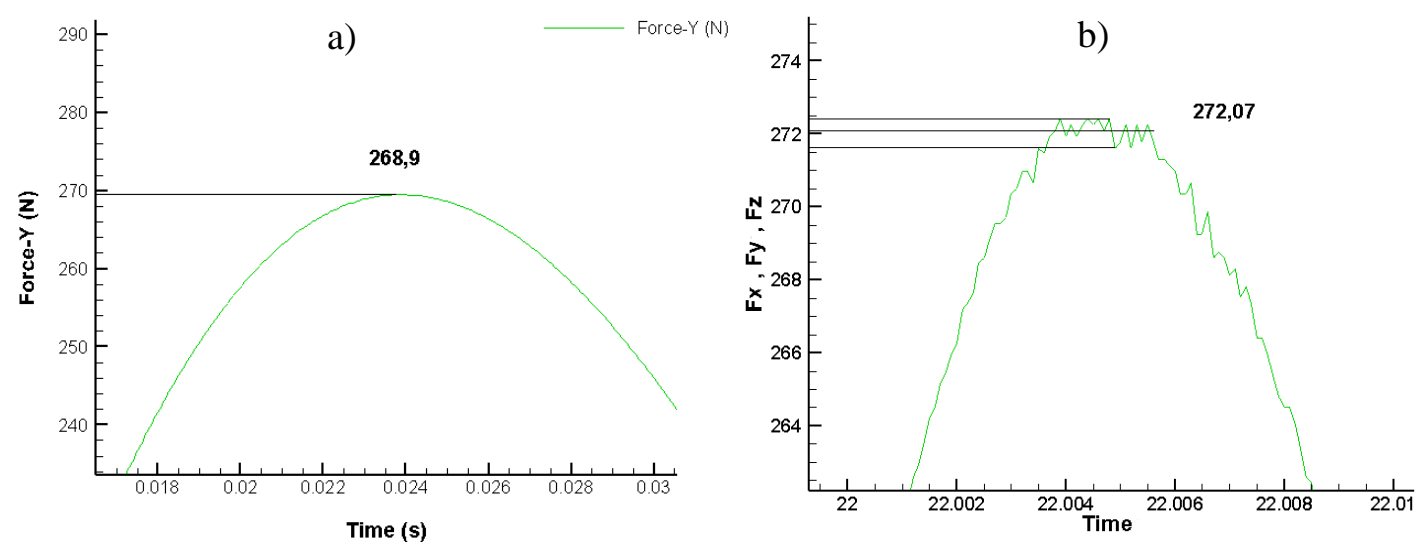

Figure 8. Simulated and measured force values for Fy: a) simulated; b) measured

The force Fy, which is the y component of the Fc force, is the second largest of the force components. Fig. 8. shows its peak curve, and the read values for the two cases (simulation and measurement). According to the literature [16], since the main cutting force Fc is largely contained in it, it should be of the highest value. However, in the present case this is not the case due to the geometry of the insert. 

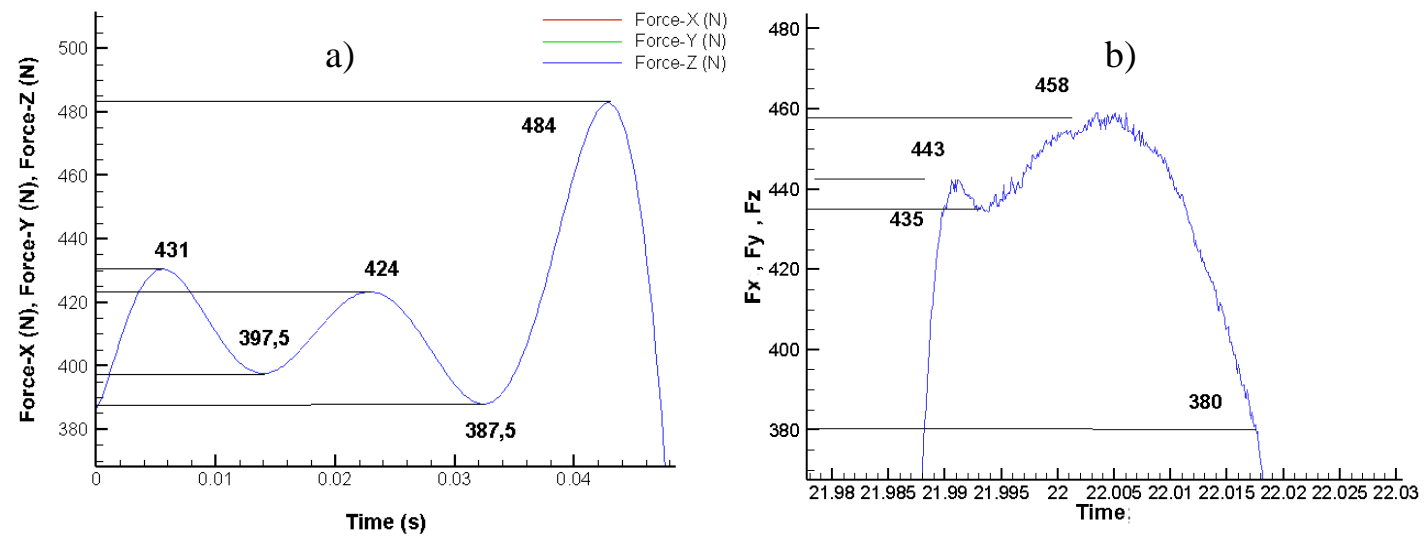

Figure 9. Simulated and measured force values for Fz: a) simulated; b) measured

The diagram in Fig. 9. shows that the Fz force is relatively linear compared to the other forces, reaches the nearly-linear and nearly-horizontal phase in a relatively short period of time (which correspond to the time during which the insert enters into the cut), and falls suddenly at the exit. This force is the highest of the components because - due to the main cutting edge angle of the circular insert - the axial force must be the greatest to ensure stability of the process against dynamic effects [17]. Its maximum value is about $480 \mathrm{~N}$.

\section{Summary}

Based on the finite element simulations and cutting experiments presented in the paper, the following conclusions can be made:

- In finite element modeling of machining processes, particular attention must be paid to the precise description of the part of the tool involved in cutting. It is often not enough to rely on cutting insert data provided by manufacturers, but additional measurements may be required.

- The paper has presented a method for measuring the cutting edge radius of an insert using an optical principle that provides a more accurate view of the geometry of the cutting edge.

- With the right choice of simulation parameters, we can achieve results close to the actual machining process.

\section{Acknowledgement}

The research reported here was carried out as part of the EFOP-3.6.1-16-2016-00011 "Younger and Renewing University - Innovative Knowledge City - Institutional development of the University of Miskolc aiming at intelligent specialization" project implemented in the framework of the Szechenyi 2020 program. The realization of this project is supported by the European Union, co-financed by the European Social Fund. This work was also supported by TKA-DAAD Researcher Exchange Project No. 307695 (2019-2020). 


\section{References}

[1] Kienzle, O., Victor, H.: Die Bestimmung von Kräften und Leistungen an spanenden Werkzeugmaschinen 1952, 94:299-305

[2] Miguélez, H., Zaera, R., Rusinek, A., Moufki, A. and Molinari, A.: Numerical modelling of orthogonal cutting: Influence of cutting conditions and separation criterion, J. Phys. IV France 2006, 134:417-422 https://doi.org/10.1051/jp4:2006134064

[3] Horváth, R.: A New Model for Fine Turning Forces, Acta Polytechnica Hungarica 2015, 12(7):109-128 https://doi.org/10.12700/aph.12.7.2015.7.7

[4] Karpuschewski, B., Kundrák, J., Varga, G., Deszpoth, I., Borysenko, D.: Determination of specific cutting force components and exponents when applying high feed rates, Procedia CIRP 2018, 77:30-33 https://doi.org/10.1016/j.procir.2018.08.199

[5] Campocasso, S., Costes, J.-P., Poulachon, G., Perez-Duarte, A.: Cutting Forces Modeling in Finish Turning of Inconel 718 Alloy with Round Inserts, Advanced Materials Research 2011, 223:75-84 https://doi.org/10.4028/www.scientific.net/AMR.223.75

[6] Arrazola, P.J., Özel, T., Umbrello, D., Davies, M., Jawahir, I.S.: Recent advances in modelling of metal machining processes, CIRP Annals 2013, 62(2):695-718 https://doi.org/10.1016/j.cirp.2013.05.006

[7] Davim, J.P.: Machining - Fundamentals and Recent Advances, Springer, London, 2008, p. 362, ISBN 978-1-84800-212-8

[8] Constantin, C., Croitoru, S.-M., Constantin, G., Străjescu, E.: FEM tools for cutting process modelling and simulation UPB Scientific Bulletin, Series D: Mechanical Engineering 2012, 74(4):149-162

[9] Akkad, M.Z., Felhö, C.: Simulating the effect of depth of cut and feed rate on the force components in face milling, Multidisciplinary Sciences 2019, 9(1):65-72 https://doi.org/10.35925/j.multi.2019.1.9

[10] Sandvik Coromant: Rotating tools 2020, Catalogue, AB Sandvik Coromant, Sandviken, 2020, Sweden

[11] Pausemann, J.: Entwicklung und konstruktive Auslegung eines Schälfräswerkzeugs, sowie dessen funktionale versuchstechnische Erprobung, Diplomarbeit, Otto-von-Guericke-Universität Magdeburg, Fakultät für Machinenbau, Institut für Fertigungstechnik und Qualitätssicherung (IFQ), 2011, p. 86

[12] Dudás, I.: Gépgyártástechnológia I.: A gépgyártástechnológia alapjai， 3. kiadás， Müszaki Könyvkiadó Kft, 2011, p: 583

[13] Fulemova, J., Janda, Z.: Influence of the Cutting Edge Radius and the Cutting Edge Preparation on Tool Life and Cutting Forces at Inserts with Wiper Geometry, Procedia Engineering 2014, 69:565-573 https://doi.org/10.1016/j.proeng.2014.03.027

[14] Kundrak, J., Zebala, W., Bana, V.: Examination of cutting zone deformation occurring in hard turning by FEM simulation, Manufacturing Technology 2003, 3:3-7

[15] Zhao, T., Zhou, J. M., Bushlya, V., Ståhl J. E.: Effect of cutting edge radius on surface roughness and tool wear in hard turning of AISI 52100 steel, International Journal of Advanced Manufacturing Technologies 2017, 91:3611-3618 https://doi.org/10.1007/s00170-017-0065-Z

[16] Shaw, M.C.: Metal Cutting Principles, $2^{\text {nd }}$ Edition, Oxford University Press, 2005, p. 672 
[17] Karpuschewski, B., Kundrák, J., Emmer, T., Borysenko, D.: A new strategy in face milling inverse cutting technology, Solid State Phenomena 2017, 261:331-338 https://doi.org/10.4028/www.scientific.net/SSP.261.331 